\title{
Eugênio Gudin e as contradições liberais na controvérsia do planejamento
}

\author{
William Eufrásio Nunes Pereira* \\ Leovigildo Melgaço Tolentino Neto***
}

\section{Resumo}

O Estado de Compromisso varguista é o ambiente no qual aflorou o debate entre Eugênio Gudin e Roberto Simonsen. O período da Era Vargas ostentava um viés planejador, sendo responsável pela criação de diversos órgãos públicos no Brasil. Gudin era membro da Comissão de Planejamento Econômico (CPE), órgão integrante do Conselho de Segurança Nacional, que tinha como objetivo elaborar estudos sobre a economia brasileira. Simonsen era membro do Conselho Nacional de Política Industrial (CNPIC), órgão filiado ao Ministério do Trabalho, Indústria e Comércio. É no domínio do CNPIC que ocorre o começo da controvérsia sobre o planejamento. Esse órgão deveria discorrer sobre como o planejamento da economia brasileira seria implementado ao longo das próximas décadas. A mainstream do pensamento econômico brasileiro habitualmente classifica a atuação de Gudin como sofisticada e vencedora do debate. Este artigo busca rever essa atuação à luz de uma perspectiva mais ampla, a histórica-relativista. Essa abordagem está em concordância com os acontecimentos da época, que surgiram à luz da Segunda Guerra Mundial, constatando que Simonsen antecipou debates à frente do seu

Doutor em Ciências Sociais (Universidade Federal do Rio Grande do Norte). E-mail: wenpereira2014@gmail.com

** Graduado em Ciências Econômicas pela Universidade Estadual de Santa Cruz. Mestre em Ciências Econômicas pela Universidade Federal do Rio Grande do Norte. E-mail: lmelgaco@gmail.com 
tempo, ao passo que a ideologia de Gudin tanto já se mostrava inadequada para o capitalismo daquele período, como foi pulverizada pelo desenvolvimento do capitalismo moderno.

\section{Introdução}

O debate sobre industrialização está arraigado a uma clássica polêmica dentro da economia, que ganhou fôlego ao longo do século XX: planejamento e intervencionismo, de um lado, versus livre mercado, de outro.

O debate intitulado por Tavares (2010) como "a controvérsia do planejamento" se desencadeou em torno da Missão Cooke, durante o Estado Novo varguista, em plena Segunda Guerra Mundial. A Missão Cooke, uma ampla pesquisa proposta e realizada pelo governo estadunidense, constatou que o Brasil estava bastante atrasado economicamente em relação às grandes economias do mundo.

Eugênio Gudin, ao longo da sua trajetória acadêmica e política, utilizou as experiências fracassadas de países autodenominados socialistas para atacar os pilares clássicos das teorias desenvolvimentistas: política industrial e planejamento econômico. Utilizava sua envergadura intelectual para defender, escancaradamente, os interesses da elite agroexportadora e do capital internacional (COLEN, 2013).

Simonsen, ao contrário, atestava que o Brasil, enquanto se conformasse com a identidade de mero exportador de insumos para os países desenvolvidos, defrontar-se-ia com os seguintes problemas: I) balança comercial desfavorável; II) desvalorização monetária; III) distribuição de renda aquém da necessária para reduzir os níveis gerais de pobreza (ABREU, 2010).

Ciente da condição desvantajosa e do atraso do Brasil em relação ao desenvolvimento de suas indústrias, em comparação aos países desenvolvidos, Simonsen atestava que essa defasagem só poderia ser superada se o Estado se mobilizasse para atuar nos seguintes setores: I) investigação científica; II) inventos; III) proteção a patentes da economia brasileira, de modo a incentivar a pesquisa e o investimento pesado de capital nas indústrias. Em suma, ele desejava que o Estado, literalmente, criasse uma classe industrial nacional (TAVARES, 2010). 
O duelo entre Eugênio Gudin e Roberto Simonsen foi travado às custas da resposta para uma pergunta: o Estado deve ser um mero observador da economia de mercado ou um agente promovedor do desenvolvimento planejado?

Ao longo do debate acerca da controvérsia do planejamento, Gudin e Simonsen discutiram essas questões com notável profundidade e afinco pelas ideias defendidas. Essa pesquisa busca expor as contradições existentes no discurso de Eugênio Gudin na "controvérsia do planejamento".

\section{Questões metodológicas acerca do debate}

Adotar uma perspectiva metodológica à luz da dimensão histórica é a janela que abre oportunidades para acrescentar alguma contribuição ao notório aporte que Simonsen deu à "controvérsia do planejamento".

Para firmar um posicionamento crítico em relação a Eugênio Gudin nesse debate, é necessário se guiar pelo viés historicista, analisando como se delineou o planejamento da economia brasileira após a Segunda Guerra Mundial. Do contrário, se fosse adotada uma metodologia ortodoxa, esta pesquisa se inclinaria em total concordância ao pensamento do autor.

No campo da história do pensamento econômico, há a possibilidade de tipificar duas linhas de abordagens: absolutista e relativista.

Blaug (1962), seguindo uma metodologia schumpeteriana, define a abordagem absolutista como aquela que é mais focada em realizar uma história da análise econômica. De acordo com Curi (2011, p. 3): "O historiador absolutista sente-se à vontade para identificar os erros e limitações de uma teoria com base em sua visão presente".

Conforme Schumpeter (1964, p. 65):

O pensamento econômico está ligado à exposição de um amplo conjunto de políticas econômicas que seu autor sustenta tendo por fundamento determinados princípios unificadores (normativos), como princípios do liberalismo econômico, do socialismo, e etc.; ou a soma total de todas as opiniões e desejos referentes a assuntos econômicos, especialmente relativos à política governamental que, em determinado tempo e lugar, pertencem ao espírito público.

Essa abordagem absolutista está arraigada a alguns princípios metodológicos que não se coadunam ao desta pesquisa: I) abordar a teoria econômica pelo viés estritamente técnico estipularia verdades que suplantariam o contexto histórico e 
a ideologia do economista em questão; II) ao ignorar que a economia é uma ciência não neutra, a análise econômica relevaria o que determinado autor defendeu e focaria meramente nos instrumentos de análise utilizados para construir seus argumentos.

Já a análise relativista, ainda de acordo com Blaug (1962), preconiza que uma investigação de natureza mais extensa leva em consideração o contexto histórico e social sob os quais ocorrem a concepção de ideias.

Os relativistas são pesquisadores que nutrem interesses nas relações da história do pensamento econômico com o arcabouço intelectual do autor em questão. Nesse prisma, nesta pesquisa, não há a possibilidade de dissociar o pensamento dos respectivos autores do contexto histórico e das questões além da economia que o influenciaram academicamente. Conforme Curi (2011, p. 4), "a visão de mundo filosófica, a ideologia, os interesses de classe e vários outros determinantes históricos são vistos como poderosas influências atuantes sobre os economistas, em seu processo de criação de ideias".

\subsection{Fundamentos da escolha pela análise relativista}

Conforme Blaug (1983, p. 7), não existe uma resposta absoluta para a escolha do método de pesquisa. Os pesquisadores em questão devem se atentar às seguintes considerações:

Adotar uma interpretação relativista ou absolutista da matéria depende inteiramente das questões que queremos levantar. Se o comentador está interessado em explicar porque certas pessoas tiveram certas ideias em determinado tempo, ele deve olhar para além da esfera do debate intelectual para uma resposta completa. Mas se ele quer saber porque alguns economistas no passado defendiam a teoria do valor-trabalho e outros acreditavam que o valor era determinado pela utilidade, e isso não era só ao mesmo tempo e no mesmo lugar, mas em diferentes países e gerações, ele é forçado a se concentrar na lógica interna da teoria, tornando-se um absolutista.

Esta pesquisa optou pela escolha do método relativista por conta do contexto latino-americano sob o qual se desencadeou o debate. Curi (2011, p. 9) resume o debate na seguinte afirmação:

A formulação de ideias econômicas na América Latina anterior à década de 1950 não se dá com base num rigoroso debate conceitual e teórico. As elaborações de Simonsen são marcadas muito mais por uma defesa da industrialização embasada pela caracterização histórica do atraso econômico, do que por um raciocínio teórico conceitual baseado em modelos

Teoria e Evidência Econômica - a. 24, n. 51, p. 339-366, jul./dez. 2018 
econômicos. Por outro lado, é certo que pensadores liberais, como Eugênio Gudin, realizaram estudos formais em economia, mas isso não significa que tenham usado seu potencial intelectual e criativo para avançar, em sentido analítico, modelos preexistentes, acrescentando ou modificando conceitos. $\mathrm{O}$ esforço de Gudin se refere à adaptação das formulações ortodoxas tradicionais à realidade brasileira, que o preocupava diretamente e sobre a qual era chamado a agir e a se posicionar.

Por esses motivos, esta pesquisa não utiliza o método schumpeteriano absolutista, calcado apenas na análise de ideias puras. Ao longo desta pesquisa, realiza-se uma abordagem sobre o arcabouço intelectual de Gudin e uma análise crítica da sua atuação no debate, sendo o método relativista a ferramenta que expõe claramente como as suas ideias pouco contribuíram positivamente para a construção do Brasil ao longo do século XX.

\section{Contexto histórico do debate}

A Era Vargas não marcou apenas o fim da República Velha, a queda das oligarquias agrícolas no campo máximo da política e a primeira experiência democrática da nova república. No âmbito do que será discutido ao longo desta pesquisa, ela também pode ser compreendida como um período de transição de um país cuja economia era essencialmente agroexportadora para uma economia industrial; de uma sociedade campestre arraigada às estruturas tradicionais para uma sociedade urbana e moderna; e, mais importante, de um Estado liberal, oligárquico e refém das elites agrárias para um Estado planejador-progressista e intervencionista (FONSECA, 2004).

Essa pujante transição é o mais notório símbolo do contexto histórico em que ocorre a "controvérsia do planejamento". Ao longo da Segunda Guerra Mundial, Vargas manteve negociações econômicas e bélicas com o fascismo, com os demais países do eixo, e, por fim, se juntou aos aliados. $\mathrm{O}$ ambiente de guerra modelou um comportamento ambíguo nos chefes de Estado dos países periféricos, especialmente os que estavam mais distantes e não precisavam escolher imediatamente um lado. O medo de fazer escolhas erradas e de se aliar ao lado perdedor modelou também o caráter de Vargas no tocante à estrutura de Estado que delineou seu governo. Ao passo que Vargas promoveu o desenvolvimentismo progressista, ele manteve liberais no seio do seu governo, como Gudin, que frearam a total guinada do Estado brasileiro ao intervencionismo planejador (DINIZ, 2004). 
É salutar ressaltar que tais mudanças, de governo provisório e constitucional para a ditadura do Estado Novo, emergiram como fruto de uma transição política e econômica que buscava acalmar as divergentes forças hostis que duelavam perante a sociedade brasileira. Tornar-se-ia incompreensível estudar a Era Vargas sem dissecar um termo amplamente utilizado por Fausto (2006): "Estado de Compromisso".

Conforme Sousa (1984, p. 7):

No chamado "Estado de Compromisso", Getúlio Vargas incorporou a função de intermediador dos interesses dos vários grupos que atuavam na esfera política. Nesse sentido, observamos que os grandes cafeicultores foram atendidos pelo novo governo através do Conselho Nacional do Café, desenvolvido com o propósito de aprimorar as formas de plantio do grão e, principalmente, estabelecer o controle dos preços do produto no mercado externo.

Voltando-se para a esfera urbana, Vargas também agiu ativamente nos conflitos que marcaram a relação entre os grupos empresariais e a classe operária. Ao invés de se postar como representante exclusivo de um único lado, Vargas teve a preocupação de fomentar ações que atendiam às demandas da burguesia industrial ao se preocupar com a expansão da indústria de base através do investimento estatal. Por outro lado, agraciava as classes trabalhadoras com direitos e benefícios nunca antes concebidos na lei do país.

Dessa forma, a sensação de que um determinado grupo social organizava a esfera política se enfraquecia, dando lugar a imagem particular de Getúlio Dorneles Vargas.

Essa ascensão do planejamento e a consequente queda do Estado liberal convergem para um período histórico marcado por grandes crises políticas e econômicas. Os primeiros decênios do século XX foram caracterizados por marcos revolucionários, como a Revolução Russa, por exemplo; pela ascensão de governos totalitários, como o Nazismo e o Fascismo, por exemplo; e por uma forte contraposição às ideias de livre mercado, sendo a queda do padrão-ouro clássico e a criação do Federal Reserve System (Banco Central Americano) os principais adventos que aumentaram o poder do Estado na esfera econômica. A reestruturação do Estado brasileiro se atrelou a essas mudanças pelas quais passavam o capitalismo global.

Na primeira metade do século XX, o mundo se dividiu em dois grandes blocos, um capitalista e outro socialista. O planejamento econômico, embora aplicado em diferentes graus, foi uma ferramenta amplamente utilizada por ambos. Conforme Hobsbawn (1995, p. 52-53), o início do século XX foi frisado por uma "era da catástrofe", período que corresponde às três décadas de um transcurso que compreende

Teoria e Evidência Econômica - a. 24, n. 51, p. 339-366, jul./dez. 2018 
desde o despontamento da Primeira Guerra Mundial até a rendição do Japão, na Segunda Guerra Mundial.

O desgastante envolvimento em embates bélicos converteu economias industriais de bens e serviços em economias de guerra. Nesse percurso, eclodiu um persistente déficit fiscal em consequência do financiamento desses grandes conflitos. Nesse enredo, Hobsbawn (1995, p. 55) assinala a queda da rigidez do padrão-ouro clássico como fator preponderante na transformação dos tesouros nacionais e seus respectivos ministérios de finanças em dirigentes das economias bélicas: "Se se tinha de travar a guerra em escala moderna, não só seus custos precisavam ser levados em conta, mas sua produção - e no fim toda a economia - precisava ser administrada e planejada".

Nas décadas entreguerras, a ortodoxia econômica postuladora do livre mercado foi perdendo confiança à medida que os países capitalistas entravam numa crise sem precedentes. Todo o mundo ocidental, sem exceção, foi atingido. No Brasil, resultou no rompimento da estrutura política vigente e na falência do modelo primário-exportador. Entretanto, o bloco socialista, que possuía a matriz econômica planejada, foi menos atingido pela crise do período.

Conforme Curi (2011, p. 14):

O Estado que emergiu na Rússia após a Revolução de 1917, a União Soviética, foi comparativamente menos atingido pela crise do que os países capitalistas, o que contribuiu para a desconfiança do mundo ocidental com relação ao livre-mercado, sendo evidenciadas as possibilidades que a planificação econômica representava.

O debate entre Gudin e Simonsen ocorreu no contexto de ascensão do Estado de Compromisso, com viés estritamente planejador, que criou uma infinidade de órgãos públicos no Brasil, entre as décadas de 1930 e 1950. Gudin era membro da $\mathrm{CPE}$, órgão que integrava o Conselho de Segurança Nacional e tinha como objetivo elaborar estudos sobre a economia brasileira, além de realizar pesquisas de diligências militares. A CPE deveria projetar o alicerce institucional que realizaria o planejamento econômico nacional. Simonsen era membro do CNPIC, órgão filiado ao Ministério do Trabalho, Indústria e Comércio.

É no domínio do CNPIC que ocorre o começo da controvérsia sobre o planejamento entre Gudin e Simonsen. Esse órgão deveria discorrer sobre como o planejamento da economia brasileira seria de fato implementado. Simonsen sugeria que o CNPIC se estabelecesse como órgão máximo na elaboração e execução do 
planejamento econômico brasileiro, subordinado apenas ao presidente da República. A outra proposta de planejamento, confeccionada por Romulo de Almeida, propunha a elaboração de um Conselho Nacional, orientado pelo presidente da República e integrado por alguns outros ministros de Estado.

O projeto final entregue a Getúlio Vargas era uma confluência dessas duas propostas. No entanto, o projeto foi rejeitado e, ao ser submetido anteriormente à CPE, originou o debate entre Gudin e Simonsen (TAVARES, 2010).

Como citado anteriormente, Getúlio Vargas, diante de um mundo sob constante incerteza, mostrava-se receoso em tomar decisões erradas. O próprio estabelecimento do Estado de Compromisso denotava a necessidade que Vargas tinha de conviver com ideias antagônicas.

Curi (2011, p. 17) reafirma a constante indecisão que delineava as ações de Getúlio Vargas:

As interpretações tradicionais do episódio apontam que a CPE teria sido criada para neutralizar o radicalismo da posição industrialista e nacionalista de Roberto Simonsen. Alternativamente, seria uma tentativa de Vargas de não perder o controle da política econômica ou mesmo de encontrar uma "via intermediária" para o desenvolvimento da economia brasileira, com elementos da posição pró-indústria e elementos de uma concepção mais liberal.

Draibe (1985, p. 43) ressalta que variáveis interpretativas analisam o problema de forma superficial, esquecendo-se de uma relevante questão: toda indecisão coordenativa do Estado de Compromisso põe em dúvida os limites da autonomia de um Estado que, quase sempre, demonstrava-se frágil:

É nesse campo instável de relações que se funda, a meu ver, a autonomia do Estado. Uma autonomia que não era nem plena, nem absoluta: enraizava-se numa multiplicidade de forças políticas heterogêneas, mas que tinham um sentido social e expressavam relações de poder definidas na luta política. Assim, se a heterogeneidade e a incapacidade hegemônica das classes sociais fundaram a autonomia do Estado, as correlações instáveis de força definidas no campo da luta política demarcavam não apenas os limites em que se exercia esta ação autônoma, como o sentido que ela haveria de ter.

O Brasil da Era Vargas foi um país que viveu a fundação do capitalismo de Estado num decurso profundamente acelerado. Esse processo ocorreu sobre alicerces econômicos e sociais conflitantes; responsáveis, em grande parte, pelo atraso do Brasil. A estrutura política resultante dessa intensa luta de classes foi o Estado de Compromisso, na qual nenhuma das esferas econômicas obteve completo domínio do aparelho do Estado, para delinear um processo de desenvolvimento homogêneo. 
O debate entre Gudin e Simonsen mostrou que, ao passo que o Estado varguista foi centralizador e industrializante, limitou-se pela própria conjuntura que o edificou.

\section{Eugênio Gudin, a retórica do "liberalismo caboclo"}

A tradição agroexportadora, norteadora do pensamento econômico brasileiro até meados de 1930, foi liberal, segundo consenso dos historiadores brasileiros. A base macroeconômica da teoria liberal reside num princípio bem básico de economia que emergiu da escola clássica, com Jean Batist Say: toda oferta gera sua demanda. Isso, no longo prazo, concebe a economia sempre em equilíbrio e em pleno emprego, isto é, a oferta agregada e a demanda agregada vivem coadunadas (ABREU, 2010).

Crises internacionais - principalmente a de 1929 -, transformações políticas e sociais desencadeadas durante o século XX abalaram os alicerces teóricos dos liberais clássicos. Para não cair no ostracismo, a própria ideologia liberal necessitou se acoplar a um processo de reinvenção capaz de viabilizar uma nova estrutura frente às vindouras realidades socioeconômicas. A consequência desse processo tem nome e sobrenome: neoliberalismo econômico.

Tal qual os liberais clássicos, os neoliberais também tratavam como prioridade a defesa do sistema econômico, calcados no princípio de eficiência.

De acordo com Bielschowsky (2001, p. 4), o termo neo trazia as seguintes diferenças:

[...] representa o fato de que os liberais brasileiros, em sua maioria, passaram a admitir, na nova realidade pós-1930, a necessidade de alguma intervenção estatal saneadora de imperfeições de mercado, as quais, segundo reconheciam, afetavam economias subdesenvolvidas como a brasileira. Esta posição é análoga à dos liberais que fizeram concessões ao keynesianismo, admitindo medidas anticíclicas como forma de recondução de economias desenvolvidas à situação em que, segundo acreditavam, os mecanismos de mercado poderiam voltar a garantir equilíbrio e eficiência.

Três características delineavam o posicionamento dos economistas adeptos ao neoliberalismo, no Brasil:

- eram defensores do Estado Mínimo, isto é, clamavam pela redução da intervenção estatal na economia brasileira; 
- expressavam-se estritamente favoráveis à implantação de políticas de austeridade fiscal coadunadas às políticas de equilíbrio monetário e financeiro;

- manifestavam-se, com frequência e radicalismo, contra políticas de cunho desenvolvimentista defensoras de projetos de industrialização nacional.

Gudin, tanto por seus admiradores quanto por seus críticos, não era reconhecido como um economista teórico. Como comumente são os monetaristas, foi perfeitamente aplicado. Buscava, com os instrumentais ortodoxos, entender diversas questões que lhe afligiam, tais como a inflação, os ciclos e, principalmente, o caótico comércio internacional no viés dos países subdesenvolvidos.

Bielschowsky (2001) comenta que, na principal obra de Eugênio Gudin, Princípios de economia monetária, não se encontra entre seus escritos uma discussão da teoria das vantagens comparativas. A respeito do comércio internacional, ele faz apenas tímidas incursões, atendo-se às questões relativas ao balanço de pagamentos e às taxas de câmbio.

Bielschowsky (2001, p. 6) ressalta que:

Gudin era um liberal convicto, mas atento. Preocupavam-no as deficiências de seus princípios, que ele procurava relativizar visando a sua preservação. Ou seja, seu raciocínio econômico, por um lado, assentava-se sobre o princípio clássico de que a economia capitalista tenderia a um equilíbrio de máxima eficiência sempre que os mecanismos de mercado pudessem funcionar livremente. Por outro, qualificava extensamente esse postulado central da visão liberal à luz das evidências históricas e dos avanços da teoria econômica. Admitia e discutia, por exemplo, a ocorrência de crises de causas endógenas e de depressões cíclicas. Considerava corretas as ideias de Keynes para entender os períodos de depressão, e foi um dos primeiros a divulgá-las em português, na edição de 1952 de seu livro-texto.

Tal qual preconiza a corrente neoliberal, além de aceitar algum nível de intervenção estatal, Gudin defendia que algumas outras políticas econômicas não só eram eficientes em períodos de depressão, como igualmente necessárias para evitar os ciclos econômicos; sem, contudo, abandonar a ideia de mínima intervenção nos períodos de prosperidade.

Por esse motivo, Bielschowsky (2001, p. 7) ressaltou a necessidade de analisar com cuidado os adjetivos, como conservador, por exemplo, atribuídos a Gudin:

Nem mesmo a idéia, comum no Brasil, de que ele aderia incondicionalmente às teses do FMI chega a ser perfeitamente correta. Gudin não concordava com o órgão num ponto básico de seu receituário de política monetária, ou seja, na proposição de que se deve buscar equilíbrio simultâneo no balanço de pagamentos e no sistema de preços interno. Considerava 
que as desvalorizações cambiais prejudicam o combate à inflação porque realimentam o processo inflacionário e permitem uma deterioração nos termos de troca, o que agrava o desequilíbrio externo. [...] Gudin entendia, como o FMI, que a causa do próprio desequilíbrio no balanço de pagamentos só poderia ser a inflação, mas não se mostrava disposto a arriscar frustrar a eliminação da raiz desse desequilíbrio derivado, em função de uma mera tentativa de antecipar sua correção.

Tanto a escola liberal quanto a neoliberal defendem como princípio que a economia global converge para um equilíbrio à medida que a inflação global é eliminada - contrariamente ao pensamento cepalino, que preconiza a existência de desequilíbrio externo estrutural.

Ainda conforme Bielschowsky (2001, p. 8):

Para ele [Gudin], uma interferência protecionista, ao conter artificialmente as importações, acaba afetando igualmente as exportações - e a eficiência alocativa - , porque transfere recursos produtivos das atividades exportadoras para as atividades domésticas protegidas e porque gera um superávit provisório no balanço de pagamentos, valorizando a moeda nacional e desestimulando as exportações. A eliminação da inflação, ao invés da introdução de barreiras ao comércio internacional, é que seria a fórmula para se alcançar a posição que, ao mesmo tempo, equilibra as contas externas do país e maximiza a eficiência do sistema econômico.

Para Gudin, o melhor mecanismo equilibrador é o de política de câmbio discricionária, pois a política de câmbio flutuante atrai especulações, que, na sua visão, abrem margens para a instabilidade. Preconizava, também, a exceção de períodos de grandes depressões ou guerras, a existência de uma taxa de câmbio de equilíbrio, que deveria ser manipulada pelas autoridades monetárias, fazendo essas o papel que o mercado espontaneamente fazia no extinto padrão-ouro clássico.

\subsection{Subdesenvolvimento, industrialização e agricultura à luz do pensamento de Gudin}

A perspectiva de Gudin em relação aos problemas pertinentes às especificidades dos países subdesenvolvidos foi esmiuçada em vários dos seus textos. Apesar de considerar os postulados ortodoxos da escola monetarista como os adequados para resolver os problemas econômicos no espectro geral, ele acreditava que as diferenças de estrutura (especialmente as institucionais) entre países desenvolvidos e subdesenvolvidos eram fatores relevantes para formular políticas econômicas. 
De acordo com Gudin (1952, p. 53), as equações são as mesmas, apenas os parâmetros variam. Defendendo, portanto, apenas adaptações à teoria convencional:

Quando se entende por "escola clássica" o conjunto de princípios que prevaleceram praticamente até a primeira guerra mundial, é claro que ela não se aplica hoje aos países subdesenvolvidos, nem aos próprios países desenvolvidos, sem importantes adaptações. A velha teoria do padrão-ouro, com o metal afluindo para um país, ou dele se afastando, e assim restabelecendo automaticamente o equilíbrio, a mobilidade dos fatores de produção, a flexibilidade dos salários, a influência decisiva da taxa de juros bancários, a concorrência sempre perfeita, tudo isso são premissas ou hipóteses que de há muito já passaram para os arquivos da História Econômica, não sem deixar - seja dito de passagem, - um valioso cabedal de alicerces teóricos.

Por isso, expressava a necessidade de tratar cada caso separadamente, salientando a necessidade da criação da Comissão Econômica para a América Latina (Cepal):

E não resta dúvida de que as economias de atividades predominantemente primárias (agrícolas, agropecuárias e extrativas) apresentam características comuns e distintas das dos países em que a indústria é a atividade predominante. [...]. Justifica-se, portanto, inteiramente, a organização promovida pelas Nações Unidas de uma Comissão Econômica para a América Latina (CEPAL), para o estudo especial do desenvolvimento econômico de países que, em graus diferentes, podem ser classificados como subdesenvolvidos. A todos eles tem a CEPAL procurado dar a maior assistência possível no estudo de seus problemas específicos de desenvolvimento (GUDIN, 1952, p. 52).

\section{Ainda de acordo com Gudin (1952, p. 54):}

O que há a estudar são as características da economia dos países subdesenvolvidos, não só em conjunto, como de cada um separadamente, especialmente em relação à natureza da procura e da oferta de seus produtos de comércio internacional e respectivas elasticidades - preço e renda, aos efeitos reflexos vindos do exterior, a seu comportamento cíclico etc. e - mais do que tudo- aos meios de promover a formação de capital e a melhoria de sua produtividade agrícola e industrial

Para isso, Teleginski (2010, p. 6) comenta que Gudin identificou as mais severas dificuldades enfrentadas pelas economias subdesenvolvidas:

Dificuldades de adaptação da agricultura para atender à demanda; preços decrescentes dos artigos exportáveis; alta fragilidade diante das crises externas resultante da baixa diversificação da pauta de exportações; movimento de capitais como agravante das crises cíclicas; invariabilidade das importações, geralmente composta por bens essenciais, e o alto crescimento demográfico; vulnerabilidade à inflação, decorrente da ausência de reserva de meios de produção. Essas fraquezas também eram observadas pela corrente estruturalista, que acreditava que a solução se encontrava na industrialização propiciada pelo Estado.

Teoria e Evidência Econômica - a. 24, n. 51, p. 339-366, jul./dez. 2018 
Todavia, Gudin preconizava que a suplantação desses percalços se daria pela adoção de políticas que viabilizassem o livre funcionamento dos mercados e a estabilidade de preços. Desse modo, o objetivo de todo sistema econômico deveria estar à guisa da estabilidade cambial e monetária. Para tal, expressava a necessidade de adoção de algumas medidas compensatórias que seriam capazes de atenuar os efeitos das oscilações dos produtos oriundos do setor primário. Feito isso, no longo prazo, alcançar-se-ia a estabilidade, tanto monetária quanto cambial, e a eficiência do livre mercado (GUDIN, 1952).

De acordo com Bielschowsky (2001, p. 9):

O controle sobre preços e sobre a produção de produtos primários foi incluído entre as medidas compensatórias preventivas. Gudin as chamou de compensações por mercadorias (formação de estoques reguladores), em contraposição às compensações de caráter monetário, que consistiriam, basicamente, em: conter o impacto inflacionista nas fases de prosperidade, absorvendo, por exemplo, uma parcela das receitas de exportação mediante impostos ou congelando-as sob a forma de saldos bloqueados ou certificados intransferíveis; liberar esses fundos nas fases de depressão, como medida anticíclica.

Para Gudin, como extremo defensor do livre-cambismo, a estrutura econômica adequada para a economia brasileira deveria se calcar nos princípios de livre mercado, à luz da teoria das vantagens comparativas. Devido ao excesso de recursos naturais, solos férteis, etc., o Brasil deveria se manter intensivo na produção de bens primários, isto é, na agricultura, que, fomentada com crédito e avanços em tecnologia, agregaria notáveis ganhos de produtividade e, assim, alocaria recursos, via livre mercado, para o fomento à indústria.

Mais a fundo, Gudin (1952) explica que a principal razão do subdesenvolvimento reside no fato de ser muito reduzido o número de produtos de exportação dos países de economia primária, isto é, de serem muito poucos os produtos que cada um desses países produz com grande vantagem comparativa.

Essa vertente argumentativa é muito bem explicada por Ohlin (1953, p. 538):

[...] o mundo colonial, que está vendendo muitos de seus artigos, como borracha, especiarias, etc., a preços baixos, passaria provavelmente a obter $50 \%$ ou $100 \%$ a mais, sem qualquer decréscimo importante na procura dêsses produtos na Europa e nos Estados Unidos. O que impede uma reviravolta violenta nas relações de troca, de que poderia resultar a melhoria do padrão de vida dos países atrasados é o fato de que o suprimento desses produtos seria aumentado. É forçoso que isso aconteça, até que os proventos que se podem auferir no mundo colonial de outras espécies de indústrias sejam elevados mediante o aumento da produtividade. 
Por fim, Gudin (1952, p. 63) explica os motivos que lhe levavam a se opor à criação planejada de um parque industrial no Brasil:

Confesso que não me parece muito convincente a proposição e isso por duas razões: a primeira é que a instalação de indústrias de consumo de produção similar ao que já vinha sendo importado do estrangeiro encontra o mercado comprador de que carece; nem de outra forma se tem e se vem industrializando o Brasil; a segunda é que poucas são as indústrias (automóveis por exemplo) para as quais a dimensão mínima de uma unidade eficiente é excessiva para o mercado existente no país (salvo países muito pequenos ou muito pobres).

Outra modalidade da teoria do impacto é a que se refere a ausência habitual nos países subdesenvolvidos das "economias externas" em quantidade suficiente para facilitar a instalação de uma nova indústria, o que exigiria, portanto, não só o investimento correspondente a essa indústria como o necessário para prover as facilidades externas indispensáveis.

Por não entender que o Brasil possuía condições de instalar determinadas indústrias sem o apoio do planejamento estatal, Gudin entendia, de forma bem resumida, que o capital privado disponível no país deveria ser alocado nos setores em que possuíamos amplas vantagens comparativas.

\subsection{Análise da atuação de Roberto Simonsen}

Para compreender as ideias expressas por Eugênio Gudin na controvérsia do planejamento, antes é necessário absorver, mesmo que em um resumo, as ideias do seu antípoda, Roberto Simonsen.

Uma leitura pouco profunda dos escritos que compõem o debate acerca do planejamento, que é o tema central desta pesquisa, pode intuir que, em nível acadêmico, no que tange às ciências econômicas, Simonsen não era tão preparado quanto Gudin para discutir o tema industrialização. Nesse ensejo, os argumentos de Gudin se impuseram como mais embasados, tanto tecnicamente quanto teoricamente, ao passo que as propostas de Simonsen se apresentaram sob estrutura propositiva, com pouca sofisticação teórica e argumentativa.

Essa visão, no entanto, desmantela-se à medida que se tem como fato que a contribuição de Simonsen para a temática que entrelaça industrialização e desenvolvimento se dá por vias completamente distintas das utilizadas por Gudin; enquanto esse era extremamente apegado às teorias, aquele utilizava a história 
econômica tanto para explicar os motivos do atraso da economia brasileira quanto para propor soluções para o país superar a pobreza (CURI, 2014).

É quase um consenso acadêmico que a principal contribuição intelectual de Simonsen à sociedade brasileira é o seu livro intitulado História econômica do Brasil. No país, essa obra foi pioneira na área da historiografia econômica, ao explicitar um estudo minucioso da formação econômica do Brasil, desde o descobrimento até a independência.

Curi (2014, p. 8) explica mais detalhadamente como essa obra de Simonsen contribuiu para o estudo da história econômica do Brasil:

O objetivo do livro era prover material de estudo para a cadeira de História Econômica do Brasil, instituída na Escola Livre de Sociologia e Política de São Paulo. Versado na historiografia econômica brasileira e europeia em voga naquele tempo, Simonsen produz um texto erudito e rico em detalhes. Tem o cuidado de embasar com dados numéricos, ainda que precários, os seus argumentos, recorrendo às mais diversas fontes. Tendo-se em conta o livro mencionado, perde força a ideia de que a defesa da industrialização por parte de Simonsen se baseia num "vazio teórico", a menos que isso seja entendido como uma falta de domínio pleno do arcabouço instrumental da economia ortodoxa vigente em seu tempo. A leitura de sua História atesta que o autor estava armado de sólido conhecimento dos fatores determinantes da evolução econômica não só do Brasil, mas de diversos países do mundo. Simonsen reconhece a especificidade do desenvolvimento brasileiro, em relação aos países hispano-americanos e aos Estados Unidos, e descreve, para cada um dos "ciclos" pelos quais passou a economia colonial brasileira em seus vários aspectos: regime de trabalho, organização e escoamento da produção, medidas de política econômica, entre outros elementos.

Em termos gerais, como intelectual, o objetivo ao qual Simonsen se dedicava atrelava-se à construção de um nacionalismo progressista, elemento que julgava como fundamental para promover o desenvolvimento do país. Por isso, em suas obras, Simonsen tanto se dedicava a interpretar o atraso quanto buscava encontrar os meios necessários para suplantar a pobreza do país. Da sua contribuição acadêmica nasceu o primeiro projeto desenvolvimentista do Brasil; e, ao contrário do que muitos pensam, não como um argumento apaixonado ou interesseiro em defesa da industrialização, mas, sim, por enxergar no desenvolvimento das indústrias a peça chave para superar o subdesenvolvimento do Brasil (RODRIGUES, 2005).

No que se referiu às especificidades da economia brasileira, estabeleceu a impossibilidade de uma estática comparativa diretamente proporcional entre a miséria nos países desenvolvidos e subdesenvolvidos. Ao passo que nesses a pobreza resulta de uma constante produção aquém do potencial, naqueles oriunda da má distribuição de renda: 
Todos ansiamos - patrões e empregados do Brasil - que aqui se estabeleça uma justa remuneração do trabalho, que todos possam viver a vida digna a que se refere o santo Papa Leão XIII em sua imorredoura 'Rerum Novarum'. Mas se a retribuição do homem é fixada em grande parte pela própria produção; se esta é de pequeno valor em relação ao volume de mão de obra disponível, como obter um elevado quociente se o divisor é fraco e o dividendo cresce continuadamente? (SIMONSEN, 1969, p. 18).

Adiante, o autor explicou como a construção de uma consciência nacional foi elementar para catalisar o desenvolvimento econômico dos países ricos:

Procuraremos determinar, pela evolução comparativa entre os povos, a razão do atraso de nossas atividades econômicas em determinadas épocas e para determinadas regiões. Esforçar-nos-emos, enfim, por indagar a origem dos muitos entraves que dificultaram e dificultam, a nossa evolução progressista. A um estudioso sincero de nossas questões econômicas uma conclusão, porém, desde logo se impõe: os povos que hoje se contam na vanguarda do progresso e da civilização libertaram-se, nos tempos modernos, de uma desorganização que os estiolava; e a primeira manifestação de sua força foi a fixação de uma consciência nacional (SIMONSEN, 1969, p. 24).

Simonsen fundou, no Brasil, uma escola desenvolvimentista que passou a investigar os problemas referentes ao desenvolvimento econômico pelo método histórico. Esse avanço tornou-se fundamental, algumas décadas depois, para a consolidação do método histórico-estruturalista, que se tornou uma importante via alternativa, na esfera do pensamento econômico da américa latina, às doutrinas liberais.

A historiografia econômica, portanto, é o elemento basilar para aludir a compreensão de uma realidade conflituosa. Por exemplo, nesse período, as ideias econômicas dominantes, propagadas pela corrente liberal, alicerçavam-se na teoria ricardiana das vantagens comparativas. Desse modo, defendia-se que o Brasil deveria explorá-las ao máximo. A realidade, no entanto, massacrava a teoria: embora o Brasil fosse o maior produtor de café do mundo, era um país dependente, economicamente fraco e incapaz de fornecer um nível de vida aceitável à sua população, além de ostentar uma estrutura industrial extremamente atrasada (GUDIN; SIMONSEN, 2010).

Nesse tocante, Gudin e Simonsen (2010) fizeram uma breve menção a países que utilizaram um alto grau de intervenção estatal para alavancar suas indústrias, além de tecer uma dura crítica ao dogmatismo das escolas liberais:

Não fosse o temor de me tornar fastidioso e poderia estender-me aqui em considerações sobre os planejamentos em estudo na Índia, na China, Austrália, Rússia, Grã-Bretanha, 
México Turquia, Chile e numerosos outros países que não querem ficar, por assim dizer, cozinhando a solução de seus problemas em "banho-maria" por amor a dogmas e doutrinas formuladas por filósofos economistas, mas que preferem parioticamente resolver, com urgência e de modo objetivo, as dificuldades nacionais (GUDIN; SIMONSEN, 2010, p. 161).

A industrialização é o tópico central do pensamento simonseano. Para o autor, tomando como base uma perspectiva histórica, a solução para as dificuldades nacionais, no caso do Brasil, era a industrialização planejada e dirigida pelo Estado, uma vez que os países que se industrializaram alcançaram altos níveis de desenvolvimento econômico. O Brasil, então, deveria seguir o mesmo caminho.

Eis um breve resumo do plano simonseano para modernizar o Brasil:

As maiores verbas da planificação seriam, sem dúvida, utilizadas na eletrificação do país, na mobilização de suas várias fontes de combustíveis e na organização de seus equipamentos de transportes. Seriam criadas indústrias-chave, metalúrgicas e químicas, capazes de garantir uma relativa autossuficiência ao nosso parque industrial e sua necessária sobrevivência na competição internacional (GUDIN; SIMONSEN, 2010, p. 45).

O plano de industrialização de Simonsen, que nasceu como resposta à Missão Cooke, iria completamente de encontro ao Plano Marshall. Simonsen preconizava que esse projeto era extremamente inadequado para os países da América Latina. A proposta do plano consistia em atribuir aos países periféricos, com base nas vantagens comparativas, a mera tarefa de fornecer insumos básicos para fomentar o desenvolvimento das indústrias de bens dos países europeus (TAVARES, 2010).

\subsection{Réplica de Gudin às propostas desenvolvimentistas de Simonsen}

A resposta de Gudin a Simonsen foi sustentada basicamente sob dois pilares. Por vezes, Simonsen foi atacado na esfera teórico-econômica, à medida que Gudin narrava a supremacia teórica da ideologia liberal. Por outras vezes, Gudin levantou questionamentos pertinentes em relação aos questionáveis dados utilizados por Simonsen para sustentar a defesa da implementação de uma planificação econômica.

No que concerne às críticas teóricas, Gudin as inicia realçando falhas elementares na argumentação de Simonsen. Naquele período, não incluir o setor de serviços como um campo específico da contabilidade nacional já era um erro passível de 
causar descrédito aos dados utilizados por Simonsen. Além disso, os dados oficiais fornecidos pelo Ministério do Trabalho ostentavam, segundo Gudin, o problema de dupla contagem.

"Renda nacional" é o valor total "líquido" da produção de mercadorias e serviços. Aqui também o qualificativo "líquido" é essencial. Se se computa o valor de um par de sapatos, não se pode computar também o do couro que serviu para fabricá-lo nem o das peles que serviram para fabricar o couro, já aí está o primeiro erro elementar do cálculo da renda nacional feito pelo Ministério do Trabalho, que soma o valor do algodão com o dos tecidos de algodão, o da cana-de-açúcar com o do açúcar, o dos couros e peles com o do calçado, o da energia elétrica motora com o das mercadorias com ela fabricadas etc. (GUDIN; SIMONSEN, 2010, p. 62).

Prosseguindo com uma ácida crítica, que possuía o claro intuito de impor descrédito à argumentação de Simonsen, Gudin expôs os erros dos cálculos apresentados referentes a investimentos, fretes, lucros e juros:

Além das mercadorias e serviços "de consumo", os rendimentos auferidos, isto é, a renda nacional, correspondem, em boa parte, aos "investimentos". Aqueles que trabalham em construção de edifícios, de estradas, de máquinas, de obras de utilidade pública, de fábricas etc. recebem salários, ordenados, juros, lucros e alugueres, como remuneração de seu trabalho e de seus capitais, ao mesmo título que os que produzem mercadorias ou serviços para o consumo. Não há, pois, como deixar de computar os investimentos na renda nacional (GUDIN; SIMONSEN, 2010, p. 63).

No entanto, passada essa parte na qual Gudin foi correto e cirúrgico em apontar alguns erros argumentativos na redação de Simonsen, o restante de sua argumentação possui nível bastante questionável e passível de críticas. Como, por exemplo, no que se reporta ao mercantilismo, modelo econômico suplantado pelo capitalismo, para depois expor as vantagens do livre comércio sobre o modelo superado. De forma sagaz, o autor sugeriu que as ideias de Simonsen, se implantadas em nível global, no tocante ao controle do Estado nas relações econômicas, levaria o mundo de volta a um regime similar ao mercantilista. Entretanto, sete décadas se passaram, as principais economias do mundo se desenvolveram adotando diversas políticas protecionistas, e o mundo não voltou ao alardeado mercantilismo.

No regime mercantilista do século XVIII, os fatores de produção eram dirigidos para as atividades econômicas ditadas pela política nacionalista do Estado; a formação do artesanato orientada de acordo com o plano de produção formulado pelo Estado; o comércio exterior controlado para assegurar o acúmulo do maior stock possível de metais preciosos, velando-se para que o balanço de comércio fosse sempre "favorável"; o comércio com as colônias arregimentado pelo princípio exclusivo da troca de produtos manufaturados por matérias-primas etc.

Teoria e Evidência Econômica - a. 24, n. 51, p. 339-366, jul./dez. 2018 
Esse tipo de economia exigia evidentemente uma planificação detalhada da vida econômica do país e uma ininterrupta vigilância do Estado sobre as atividades individuais (GUDIN; SIMONSEN, 2010, p. 65).

Ao contrário dos postulados clássicos defendidos por Gudin, as duas principais economias do mundo, Inglaterra e Estados Unidos, são exemplos fidedignos de como a proteção à indústria nascente é uma política capaz de promover o sucesso de todo o processo de industrialização; tal qual, o contrário, a abertura em estágios iniciais, como feito em Portugal e Espanha, por exemplo, leva ao desastre e à miséria (RODRIGUES, 2005).

A Inglaterra é o maior exemplo de sucesso no que tange à proteção do Estado às indústrias de base. A economia britânica era especialista em políticas protecionistas e, também, na sagacidade de burlar as alfandegas de outros países (LIST, 1983).

O tratado de Methuen, também conhecido como o Tratado de Panos e Vinhos, por exemplo, foi uma política protecionista praticada pela Inglaterra que promoveu um crescimento significativo da sua industrialização. Ao contrário do que postula a ideologia liberal, ela foi desastrosa para Portugal, pois abarrotou o país de bens produzidos pelas manufaturas inglesas, ao mesmo tempo em que os ingleses tomaram posse de boa parte do ouro e da prata portugueses que eram extraídos do Brasil. Esses ganhos de comércio da Inglaterra, em parte, foram utilizados para comprar bens de manufaturas da Índia, os quais eram vendidos a um preço muito baixo para as demais economias da Europa. Essas práticas comerciais da Inglaterra, além de descapitalizar Portugal, liquidaram as indústrias alemãs e francesas (PIMENTA, 2013).

Na sequência, o autor lamentou a queda do padrão-ouro clássico, pois julgava a rigidez daquele regime ideal para conter o impulso inflacionário dos Estados. Ele reafirma que foi esse modelo, e não intervenções pontuais coadunadas a algum nível de liberdade econômica, o grande responsável pelo desenvolvimento econômico que o mundo viveu durante o século XIX e o começo do século XX:

Até 1914 a economia liberal conduziu a humanidade por essa rota, de constante aumento de bem-estar e de elevação do padrão de vida das populações. Dentro de seus padrões se abordavam e resolviam os novos problemas à medida que eles surgiam. [...]

A Guerra de 1914 veio abalar profundamente os alicerces dessa estrutura: $1^{\circ}$ ) desorganizando ou destruindo os sistemas monetários de grandes e pequenas nações até atingir a 
libra esterlina e o dólar; $2^{\circ}$ ) deslocando a liderança econômica e política das mãos experimentadas da Inglaterra para as mãos vigorosas, mas ainda inexperientes, dos Estados Unidos; 3o) criando a desordem política e econômica em toda a Europa Central e Oriental, de cujo caos nasceram as revoluções sociais, primeiro da Rússia, depois da Itália e da Alemanha (GUDIN; SIMONSEN, 2010, p. 67-68).

Ao contrário do que afirma a narrativa de Gudin, não foi a Primeira Guerra Mundial que deflagrou o primeiro golpe no padrão-ouro clássico. Desde 1870, esse modelo já vinha apresentando distúrbios e se mostrando incapaz de resolver problemas que dizia evitar. Conforme Menger (1970), um forte argumento da ideologia liberal clássica consiste no silogismo que abarca a diluição de grandes conglomerados econômicos e na prevalência de pequenos empresários pulverizados, que, no longo prazo, estariam trabalhando sob um regime de concorrência perfeita.

No entanto, ao contrário da narrativa de Gudin, o padrão-ouro clássico foi incapaz de entregar o prometido:

A partir da década de 1870, uma segunda revolução industrial iniciou-se, com o fim do livre comércio. Nesse período, começaram os trustes (organizações industriais de controle da produção e distribuição das mercadorias, com o objetivo de impor o preço dos produtos industriais a seu favor).

Uma associação, denominada cartel, manteve as empresas separadas, mas sem competir entre si, estabelecendo a divisão dos mercados e dos preços.

Os preços passaram a ser fixados pelos trustes, cartéis e holdings (uma empresa central controla outras empresas, que se mantêm autônomas, embora a maioria das ações pertençam à empresa central). $\mathrm{O}$ imperialismo se transformava pela necessidade de novas áreas de aplicação dos capitais industriais.

A partir de 1870, o fundamental era aplicar os capitais europeus excedentes e ampliá-los. A Ásia, América Latina e principalmente a África foram as regiões de penetração imperialista do século XIX.

Portugal e Espanha já tinham seus domínios na África, desde o século XVI. Mas na nova fase do colonialismo, a Inglaterra, França, Alemanha, Itália e Bélgica passariam a disputar os territórios africanos.

A penetração europeia na África foi realizada com todas as formas de violência às populações nativas. Destruição dos valores tradicionais das tribos africanas, escravidão, uso da 
força, guerras e etc., foram os métodos europeus de transformar a África em seu objetivo de exploração do imperialismo. A Ásia também tornou-se objeto de exploração imperialista (EGAS, 2008, p. 9).

No período em que ocorreu a controvérsia do planejamento, a escola austríaca de economia, à guisa de Bawerk, Menger, Mises e Hayek, já havia ganhado alguns adeptos pelo mundo. Gudin, no Brasil, mostrava-se um dos grandes entusiastas dessa escola e, direta e indiretamente, utilizou argumentos austríacos pare refutar o projeto de desenvolvimento impetrado por Simonsen (GUDIN, 1952).

Cabe resumir e comentar dois postulados da escola austríaca de economia para entender a argumentação de Gudin acerca do problema monetário. O primeiro postulado que merece destaque preconiza que qualquer impressão de dinheiro desvinculada de uma oferta real de poupança caracteriza falsificação por parte das autoridades monetárias. Pode-se perceber a total inclinação de Gudin a esse princípio no seguinte trecho:

O único meio de formar capital é o de não consumir tudo quanto se produz e destinar uma parte do produto do trabalho de hoje à construção de um melhor aparelhamento para amanhã. Até hoje não se encontrou, em país algum do mundo, outro meio de formar capital. Só os ignorantes, os literatos ou os pândegos acreditam em capital criado com papel pintado.

Moeda não é capital. $\mathrm{O}$ fato de aumentarem as notas emitidas ou os depósitos em bancos de 8 para 30 milhões de contos, não quer dizer que a renda ou a riquezas nacionais tenham crescido. Se moeda fosse meio de criar capital, não haveria mais país pobre no mundo. A inflação de meios de pagamento só faz tirar do bolso de uns para o de outros. É, como dissemos, um imposto e o pior deles.

O capital é o alicerce da riqueza das nações. A riqueza de uma nação depende da quantidade de capital utilmente investido. O padrão de vida de um país depende, pode-se dizer, do número de cavalos-vapor per capita. $\mathrm{O}$ operário americano produz mais em uma hora de trabalho porque tem, atrás de si, um maior e melhor aparelhamento mecânico. A produtividade da Grã-Bretanha em 1945 é maior do que em 1745, graças ao "acúmulo de capital produtivo" durante esses 200 anos (GUDIN, 1952, p. 56).

Para Gudin e a Escola Austríaca, afirmar que a impressão de papel-moeda não era uma política capaz de aumentar a produtividade não era tudo. Ela não só não era capaz de aumentar a riqueza, como também desencadearia um incômodo efeito colateral: inflação. 
I princípio - Uma vez atingido o "emprego total", novos empreendimentos farão subir os preços, mas não farão crescer a produção. [...]

Tem-se procurado distinguir entre investimentos produtivos, como estradas de ferro, siderurgia etc. e investimentos chamados improdutivos, novos edifícios, palácios etc. Do ponto de vista da inflação, isto é, da alta dos preços das mercadorias de consumo, a distinção não é cabível. Seja qual for o tipo de investimento, estradas de ferro, edifícios, pontes ou outros, aqueles que trabalham nessas obras recebem salários e ordenados que lhes conferem o direito de haver mercadorias de consumo, sem que entretanto possam eles trazer ao mercado outra coisa senão "uma promessa de futura melhoria da produção". Em outras palavras: aqueles que trabalham no setor de investimentos, isto é, de obras novas, vêm se abastecer dos artigos de alimentação e de vestuário de que precisam num mercado suprido somente pelos que trabalham no setor das mercadorias de consumo. É claro, portanto, que quanto maior desenvolvimento tiver o setor dos investimentos e menor o de mercadorias de consumo, mais acentuada será a alta dos preços. Isto nada tem que ver com o fato de o investimento vir a ser, de futuro, produtivo ou improdutivo (GUDIN; SIMONSEN, 2010, p. 80-82).

O segundo postulado é uma consequência lógica do primeiro. Trata-se de uma capciosa sequência de silogismos, que segue: I) o padrão-ouro clássico é perfeito e brecava completamente o potencial inflacionário do Estado; II) a impressão de papel-moeda torna o capitalismo instável, à medida que distorce as expectativas dos agentes econômicos; III) fechar todos os bancos centrais, restabelecer o padrão-ouro clássico e eliminar a impressão de dinheiro sem lastro tornariam o sistema capitalista global perfeitamente estável e virtuoso.

As assertivas supracitadas podem sem observadas na argumentação de Rothbard (2012, p. 31):

[...] a inflação não é a única consequência infeliz da expansão governamental da oferta de dinheiro e de crédito. Essa expansão distorce a estrutura do investimento e da produção, levando a investimentos excessivos em projetos insustentáveis nas indústrias de bens de capital. Essa distorção se reflete no conhecido fato de que, em todo período de boom, os preços dos bens de capital sobem mais do que os preços dos bens de consumo. Os períodos de recessão do ciclo econômico tornam- se então inevitáveis, porque a recessão é o processo corretivo necessário por meio do qual o mercado liquida os investimentos insustentáveis do boom e redireciona os recursos das indústrias de bens de capital para as indústrias de bens de consumo. Quanto mais durarem as distorções inflacionárias, piores serão os ajustes recessivos. Durante a recessão, a transferência de recursos acontece por meio de uma queda dos preços dos bens de capital em relação aos preços dos bens de consumo. Durante a depressão de 1974-1975, vimos isso ocorrer: os preços das matérias primas industriais caíram de maneira rápida e substancial, os preços do atacado permaneceram no mesmo nível ou caíram um pouco, mas os preços dos bens de consumo ainda subiram rapidamente - em suma, a depressão inflacionária. 
Como já refutado anteriormente, o século XIX não foi um legítimo período de estabilidade, como alguns historiadores liberais preconizam. Ao contrário da história narrada por eles, o capitalismo do padrão-ouro clássico chegou a atravessar uma crise econômica de três décadas consecutivas.

Sobre o reestabelecimento da velha ordem econômica, o autor foi enfático ao fazer uma analogia pontual: a implementação de tarifas alfandegárias e demais políticas comerciais intervencionistas, visando proteger a indústria nascente, como sugeriu Simonsen, faria o Brasil retroceder ao mercantilismo. Em termos generalizados, segundo ele, isso destruiria o comércio global:

O dumping é um processo a que se recorre, quase invariavelmente, com o objetivo de reduzir os stocks e sustentar os preços no país exportador, é o que fazem os sindicatos americanos da laranja, por exemplo, quando a safra dessa fruta é superabundante. No caso, não creio que haja, no momento atual, superabundância de mercadoria alguma nos Estados Unidos; ao contrário, há escassez de todas. O suposto dumping teria então sido feito com o indisfarçável propósito de esmagar indústrias brasileiras nascentes. Conhecida como é, nos Estados Unidos, a rapidez com que, em nosso atual regime político, podemos expedir legislação de emergência e conhecido também o empenho do governo brasileiro pela criação das indústrias em questão, custa a crer que se trate realmente de um golpe de dumping e não de uma simples operação comercial lucrativa em que o preço normal da mercadoria nos Estados Unidos, adicionado ao frete, seguro e direitos aduaneiros no Brasil, ainda deixa boa margem de lucro, aos preços correntes da mercadoria de produção nacional no Brasil (GUDIN; SIMONSEN, 2010, p. 97).

Se Inglaterra e Estados Unidos, como bem argumentava List (1983), adotaram políticas protecionistas, certamente, algum grau de intervenção estatal não é um veneno tão danoso à economia de mercado quanto Gudin alegava ser. O desenvolvimento do capitalismo moderno se deve, sim, a algum grau de liberdade econômica, que o mundo adquiriu à medida que ocorriam os avanços da revolução industrial. No entanto, não há como negar que os avanços de intervenções estatais pontuais foram essenciais para acelerar o crescimento econômico global e elevar as condições de vida dos mais pobres.

\section{Considerações finais}

A Missão Cooke foi um relatório estadunidense divisor de águas no que tange à ação do Estado na economia brasileira. Por mais que Gudin tenha prevalecido em 
parte do debate no campo teórico e na discussão técnica, foi o ideário simonseano que prevaleceu na construção do Brasil ao longo do século XX.

Conforme pode ser observado na historiografia econômica do Brasil ao longo do século XX, a criação do Banco Nacional de Desenvolvimento Social (BNDES), o Plano de Metas, os Planos Nacionais de Desenvolvimento (PND) I e II e o Programa de Ação Econômica do Governo (PAEG) são provas insofismáveis de que a realidade complexa do capitalismo moderno enterrou as ideias defasadas defendidas por Eugênio Gudin. Sua única vitória intelectual se restringe a um mero trecho do debate no qual ele contesta corretamente alguns erros de contabilidade social cometidos por Simonsen.

Mesmo que se levasse em consideração meramente o campo teórico, o desenvolvimento do capitalismo brasileiro ao longo do século XX traria uma derrota também intelectual a Eugênio Gudin. Conforme pode ser observado também na historiografia econômica do Brasil, boa parte do desenvolvimentismo brasileiro fluiu num decurso dirigido por economistas liberais e declarados pupilos de Gudin. Roberto Campos, Mario Henrique Simonsen e Otávio Bulhões, por exemplo, estiveram diretamente envolvidos nos principais projetos de planejamento da economia brasileira. Ou seja, quando estiveram à frente do Estado, os liberais pós-Gudin não praticaram políticas liberais.

Por fim, é notório que, ao longo do século XX, o desenvolvimento da economia brasileira se desencadeou de maneira direta a tudo que Roberto Simonsen defendeu no decorrer do debate. Está certo que o Brasil não deixou de lado sua vocação agrícola. No entanto, industrializou-se e já chegou a ter o oitavo maior Produto Interno Bruto (PIB) do mundo. Diante de tais fatos, não é possível afirmar que Estado e mercado são nocivos um ao outro. 


\title{
Eugênio Gudin and liberal contradictions in the planning controversy
}

\begin{abstract}
The Vargas State of Commitment is the environment where the debate between Eugênio Gudin and Roberto Simonsen has surfaced. This period of Era Vargas had a bias planner, being responsible for the creation of several public agencies in Brazil. Gudin was a member of the Economic Planning Commission (CPE), a member of the National Security Council, whose objective was to elaborate studies on the Brazilian economy. Simonsen was a member of the National Council of Industrial Policy (CNPIC), an organization affiliated to the Ministry of Labor, Industry and Commerce. It is in the domain of the CNPIC that the beginning of the controversy about the planning takes place. This body should discuss how the planning of the Brazilian economy would be implemented over the coming decades. The mainstream of Brazilian economic thinking usually classifies Gudin's performance as sophisticated and winning the debate. This article will seek to review this performance in the light of a broader, historical-relativistic perspective. This approach is in accordance with the events of the time that emerged in the light of World War II, noting that Simonsen anticipated debates ahead of his time, whereas Gudin's ideology was already already inadequate for capitalism of that period, as pulverized by the development of modern capitalism.
\end{abstract}

Keywords: Eugênio Gudin. Roberto Simonsen. Industrialization. Planning.

\section{Eugênio Gudin y contradicciones liberales en la controversia de planificación}

\section{Resumen}

El Estado de Compromiso varguista es el ambiente donde afloró el debate entre Eugênio Gudin y Roberto Simonsen. Este período de la Era Vargas ostentaba un sesgo planificador, siendo responsable por la creación de diversos organismos públicos en Brasil. Gudin era miembro de la Comisión de Planificación Económica (CPE), órgano integrante del Consejo de Seguridad Nacional, que tenía como objetivo elaborar estudios sobre la economía brasileña. Simonsen era miembro del Consejo Nacional de Política Industrial (CNPIC), órgano afiliado al Ministerio de Trabajo, Industria y Comercio. Es en el dominio de la CNPIC que ocurre el comienzo de la controversia sobre la planificación. Este órgano debería discurrir sobre cómo la planificación de la economía brasileña sería implementada a lo largo de las próximas décadas. La corriente del pensamiento económico brasileño habitualmente clasifica la actuación de Gudin como sofisticada y vencedora del debate. Este artículo buscará revisar esa actuación a la luz de una perspectiva más amplia, la histórica-relativista. Este enfoque está en concordancia con los acontecimientos de la época, que surgieron a la luz de la Segunda Gran Guerra Mundial, constatando que Simonsen anticipó debates al 
frente de su tiempo, mientras que la ideología de Gudin tanto ya se mostraba inadecuada para el capitalismo de aquel período, como fue pulverizada por el desarrollo del capitalismo moderno.

Palabras clave: Eugênio Gudin. Roberto Simonsen. Industrialización. Planificación.

Classificação JEL: B31, B3 


\section{Referências}

ABREU, Marcelo de Paiva. A economia brasileira: 1930-1964. 2010. 145 f. Dissertação (Mestrado) - Curso de Ciências Econômicas, Ciências Econômicas, Pontifícia Universidade Católica do Rio de Janeiro, Rio de Janeiro, 2010.

BIELSCHOWSKY, Ricardo. Eugênio Gudin. Estudos Avançados, [s.l.], v. 15, n. 41, p.1-10, abr. 2001. FapUNIFESP (SciELO). DOI: 10.1590/s0103-40142001000100009.

BLAUG, M. Economic Theory in Retrospect. 3. ed. Homewood, IL: Richard D. Irwin, 1962.

BLAUG, M. Rebel with Many Causes. Massachusets, Us: Edward Elgar Publishing Limited, 1983.

COLEN, Dalvan. A crise de 1929 pela ótica de Eugênio Gudin. Brasília, DF: Clubjus, 2013. 65 p.

CURI, Luiz Felipe. Redimensionando a contribuição de Roberto Simonsen à controvérsia do planejamento (1944-45): pioneirismo e sintonia. 2011. Disponível em: http://anpec.org.br/encontro/2011/inscricao/arquivos/148-596120f19142500e731e80b9328e2faf.pdf. Acesso em: 20 jul. 2015.

CURI, Luiz Felipe. Roberto Simonsen e a modernização no Brasil da Primeira República. 2014. Disponível em: http://diamantina.cedeplar.ufmg.br/2014/site/arquivos/roberto-simonsen-e-a-modernizacao-no-brasil-na-primeira-republica.pdf. Acesso em: 20 jul. 2015.

DINIZ, Eli. É possível um novo modelo de Estado desenvolvimentista no Brasil. Boletim de Análise Político-Institucional, Brasília, DF, Instituto de Pesquisa Econômica Aplicada, n. 1, 2004.

DRAIBE, Sônia. Rumos e metamorfoses: um estudo sobre a constituição do Estado e as alternativas da industrialização no Brasil. Rio de Janeiro: Paz e Terra, 1985.

EGAS, Karen. O capitalismo financeiro. 2008. Disponível em: https://docs.google.com/document/d/1afwH. Acesso em: 20 jul. 2015.

FAUSTO, Boris. Getúlio Vargas - o poder e o sorriso. São Paulo: Cia das Letras, 2006. 264 p.

FONSECA, Pedro Cesar. O ideário de Vargas e as origens do estado: desenvolvimentista no Brasil. Porto Alegre: Universidade Federal do Rio Grande do Sul, 2004.

GUDIN, Eugênio; SIMONSEN, Roberto C. A controvérsia do planejamento na economia brasileira. Rio de Janeiro: Ipea/INPES, 2010.

GUDIN, Eugênio. Princípios de economia monetária. Rio de Janeiro: FGV, 1952.

HOBSBAWN, Eric. Era dos extremos - o breve século XX. São Paulo: Companhia das Letras, 1995. $632 \mathrm{p}$.

LIST, Georg Friedrich. "A História”. In: SISTEMA Nacional de Economia Política. São Paulo: Abril Cultural, 1983.

MENGER, Carl. Principles of Economics. 3. ed. New York: Createspace Independent Publishing Platform, 1970. 328 p.

OHLIN, Bertil. Interregional and International Trade. 3. ed. Massachusets, Us: Harvard University, $1953.324 \mathrm{p}$.

RODRIGUES, Carlos Henrique Lopes. O debate entre Roberto Simonsen e Eugênio Gudin na controvérsia sobre o planejamento econômico. In: CONFERÊNCIA 33 INTERNACIONAL DE 
HISTÓRIA ECONÔMICA, 4; ENCONTRO DE PÓS-GRADUAÇÃO EM HISTÓRIA ECONÔMICA, 4. São Paulo, 2005.

ROTHBARD, M. N. A grande depressão americana. Trad. Pedro Sette-Camara. São Paulo: Instituto Ludwig Von Misses Brasil, 2012.

SCHUMPETER, Joseph. A Theory of Social and Economic Evolution. Austria: Palgrave Mcmillian, 1964.

SIMONSEN, Roberto. Evolução Industrial do Brasil e outros estudos: seleção, notas e bibliografia. São Paulo: Editora Nacional; Editora da USP, 1969.

SOUSA, Maria Cecília. Industrialização, Estado e sociedade no Brasil (1930-1945). 1984. Disponível em: http://www.scielo.br/scielo.php?script=sci_arttext\&pid=S0034-75901984000300006. Acesso em: 19 jul. 2015.

TAVARES, Maria da Conceição. A controvérsia do planejamento na economia brasileira. Rio de Janeiro: Ipea; Inpes, 2010.

TELEGINSKI, Jaqueline. Gudin e o Pensamento Liberal. São Paulo: FAE USP, 2010. 